\title{
CONTEXTUALIZANDO A ABORDAGEM DE RADIAC̣̃̃ES NO ENSINO DE QUÍMICA
}

\author{
Miguel de Araújo Medeiros* \\ Anderson César Lobato**
}

RESUMO: Este trabalho consiste em: (i) análise do conteúdo radiação em livros didáticos de Química e Física; (ii) análise das concepções prévias dos alunos sobre radiação; (iii) desenvolvimento e aplicação de um material didático para suporte ao ensino e aprendizagem de radiação e (iv) análise do conhecimento adquirido pelos estudantes após o estudo do conteúdo. A análise dos livros didáticos de Química mostrou que radiação nuclear é o conteúdo principalmente abordado, enquanto que nos livros de Física são apresentadas principalmente ondas eletromagnéticas. Esse resultado demonstra que o conteúdo não foi ensinado de maneira eficiente. O conhecimento prévio, observado através de questionário, identificou as principais dificuldades dos alunos. Neste contexto, um material didático foi desenvolvido para o ensino e aprendizagem de radiação para minimizar a ideia errada de que a radiação é prejudicial (como foi identificado em $82 \%$ das respostas dos estudantes). Através do ensino de radiações, usando esse material, e analisando os resultados deste trabalho, foi possível verificar que os alunos se interessam pelo assunto, reconhecendo e diferenciando vários tipos de radiação presentes no cotidiano.

Palavras-chave: Radiação; Ensino e Aprendizagem; Contextualização; Material Didático.

\section{CONTEXTUALIZING THE APPROACH OF RADIATION IN THE TEACHING OF CHEMISTRY}

ABSTRACT: This work is consisted of: (i) analysis of the content of radiation in chemistry and physics textbooks; (ii) analysis of the students' previous knowledge of radiation; (iii) development and implementation of a didactic material to support the teaching and the learning of radiation; and (iv) analysis of the knowledge acquired by the students after the study of the contents. The analysis of chemistry textbooks showed that the only content is nuclear radiation, while physics textbooks presented only electromagnetic waves contents. It demonstrates that the contents are not efficiently taught. The previous knowledge was observed through questionnaires that identified main difficulties of the students. In this context, a didactic material was developed for teaching and learning radiation to minimize the wrong idea that radiation is harmful (as identified in the $82 \%$ of students answers). By teaching radiation, using this material, and analyzing the results of this work, it was possible to check that the students are interested in the subject and recognize and differentiate several types and sources of radiation present in everyday life.

Keywords: Radiation; Teaching and Learning; Contextualization; Teaching Material. 


\section{INTRODUÇÃO}

Ao abordar conteúdos de Química na educação básica, percebe-se que muitas vezes o que é ensinado em sala de aula não tem relação com o cotidiano do aluno, nem com o que é desenvolvido (pesquisas) em universidades ou centros de pesquisas (MUNFORD \& LIMA, 2007). Acredita-se, então, que não há relação entre o conteúdo lecionado, o conhecimento desenvolvido em pesquisas e o conhecimento já adquirido pelo aluno em suas experiências de vida e escolar, podendo se transformar em motivo de insatisfação, desmotivação e dificuldades na aprendizagem dos conteúdos propostos em sala de aula. Brown et al (1989) sugerem que, quando o raciocínio dos estudantes é trabalhado nos moldes do ensino tradicional, pode produzir, de forma mecânica, significados e conceitos fixos, difíceis de serem transpostos, restringindo a visão do estudante sobre o conteúdo.

A motivação do aluno pode surgir quando o assunto trabalhado desperta o seu interesse. Assim, ele verá na aprendizagem a satisfação de sua necessidade de conhecimento (RICARDO, 2003). É possível que, ao trabalhar situações do dia a dia em sala de aula, buscando o conhecimento científico para explicá-las, o aluno seja mais capaz de relacionar o conhecimento químico com sua vida. Dessa maneira, entende-se que a contextualização do ensino tem relação com a motivação do aluno, por dar sentido àquilo que ele aprende, fazendo com que relacione o que está sendo ensinado com sua experiência cotidiana.

Pomeroy (1994) acredita que é necessário, para a educação científica, trabalhar as relações entre ciência, tecnologia e sociedade dentro do cotidiano dos estudantes, assim como Godim e Mól (2008) acreditam que deve existir uma inter-relação entre os saberes populares e o que é ensinado em sala de aula, para o desenvolvimento mais amplo dos estudantes.

Para alcançar esse objetivo podem-se utilizar objetos e fenômenos presentes no cotidiano para mostrar como determinadas tecnologias se valem do conhecimento científico para o desenvolvimento atual da sociedade, conforme estabelecido nos Parâmetros Curriculares Nacionais do Ensino Médio (BRASIL, 2002). Neste contexto, acredita-se que, por exemplo, o ensino de radiações pode ser apoiado em material didático que aborde o conteúdo de maneira contextualizada, mostrando avanços tecnológicos promovidos pela utilização das radiações e as formas de interação com a matéria, descrevendo-as e explicando-as, diferentemente de como o conteúdo é abordado em alguns livros didáticos de Ensino Médio.

A cada dia, novas tecnologias que envolvem radiações são desenvolvidas nos mais diversos campos da atividade humana, possibilitando a execução de tarefas impossíveis ou de grandes dificuldades pelos meios convencionais (CARDOSO, 2000). E, algumas vezes, os estudantes podem perder a oportunidade de aprender mais sobre o que ocorre no mundo que os cerca, pelo fato de os currículos de Física, Biologia e Química (PEREIRA, 1997) ou os livros didáticos, muitas vezes, não apresentarem os conteúdos de forma contextualizada. 
No ensino de Ciências, em especial de Química, os livros didáticos constituem um recurso de fundamental importância, já que representam, em muitos casos, o único material de apoio didático disponível para alunos e professores. Portanto, por ser um dos importantes componentes do cotidiano escolar em todos os níveis de ensino, acredita-se que sua análise possa contribuir para a compreensão de uma parte do complexo sistema escolar, principalmente no que se refere à elaboração de material didático de maior qualidade para a educação.

\section{METODOLOGIA}

Para analisar o tratamento dado ao tema radiação nos livros didáticos de Química e Física do Ensino Médio, foram selecionados seis livros presentes na Portaria no 366, de 31 de janeiro de 2006, publicada na edição número 23 do Diário Oficial da União, em 01/02/2006, que fazem parte do Programa Nacional do Livro para o Ensino Médio (PNLEM) ${ }^{1}$ e estavam disponíveis para a análise deste trabalho.

A análise das obras de Química foi efetuada apenas em capítulos que abordam diretamente o tema radiação. Percebeu-se que os livros, ao abordarem o conteúdo, tratam principalmente das radiações nucleares, não as vinculando às ondas eletromagnéticas, apresentadas no capítulo sobre modelos atômicos. Já os livros de Física abordam principalmente alguns aspectos das radiações eletromagnéticas.

Para verificar e analisar as concepções dos estudantes sobre radiação, foram selecionadas duas turmas de $3^{\circ}$ ano do Ensino Médio (77 alunos), em 2008, em uma escola da rede pública estadual, na Região Metropolitana de Belo Horizonte. A estes alunos, aplicou-se um questionário, estruturado pelos autores deste trabalho, composto pelas seguintes questões:

1. Você já ouviu falar sobre radiações? Onde?

2. Como você definiria o termo radiação?

3. Radiação causa benefícios ou malefícios? Quais?

4. Hoje, ou em algum dia de sua vida, você já ficou exposto a algum tipo de radiação? Qual(is)?

5. Quais são os tipos de radiação de que você já ouviu falar? Cite-os.

Após o questionário ser aplicado² nas turmas de Ensino Médio, analisou-se o conteúdo das respostas fornecidas pelos estudantes. A partir daí, desenvolveu-se um material didático para abordar os diversos tipos de radiações presentes no cotidiano dos estudantes, utilizando o princípio tecnológico de alguns dispositivos cotidianos (rádio, TV, forno de micro-ondas, telefone celular, etc.) para desenvolver a temática do conteúdo.

Em um último momento, aplicou-se novamente o questionário aos alunos para avaliar o conhecimento adquirido ao estudar o conteúdo de maneira contextualizada. 


\section{RESULTADOS E DISCUSSÃO}

\section{Análise dos livros didáticos de Ensino Médio}

Dentre os seis livros selecionados, quatro são para a disciplina de Química e dois para a de Física. Os livros foram designados como Q1, Q2, Q3, Q4 (livros de Química) e F1, F2 (livros de Física).

A seguir, estão descritos os itens que mereceram atenção especial pelo tratamento a eles dispensado nos livros.

\subsection{Parte do conteúdo em que 0 assunto é abordado:}

Nos livros Q1 e Q2 o tema radiação é tratado principalmente em capítulos sobre radiação nuclear, abordando principalmente emissões $(\alpha, \beta, \gamma)$, leis e cinética de desintegração radioativa, citando alguns acidentes envolvendo esse tipo de radiação. No capítulo sobre modelos atômicos é dada atenção à radiação eletromagnética ( $\mathrm{X}$ e visível), quando é abordada a descoberta da radioatividade e o modelo atômico de Bohr. Embora radiações nucleares e algumas eletromagnéticas sejam descritas nas obras (livros Q1 e Q2), falta uma ligação entre os conteúdos, o que possivelmente dificulta a criação de relação entre esses dois tipos de radiação pelos estudantes. E essa falta de ligação entre os conteúdos acaba deixando a falsa impressão de que os conteúdos não se relacionam.

No livro Q3 o tema radiação é abordado em pelo menos três capítulos. Dois capítulos do livro são destinados a discutir a relação entre radioatividade, energia nuclear e o átomo. Nestes capítulos são abordados aspectos da estrutura eletrônica do átomo e estabilidade nuclear, relacionando-a a radiação e energia nuclear, descrevendo as emissões $(\alpha, \beta, \gamma)$, as leis e cinética de desintegração radioativa e também o que são usinas e lixo nuclear. Em outro capítulo, sobre modelos atômicos, as radiações eletromagnéticas ultravioleta, visível e X (além das radiações $\alpha$ e $\beta$ ) são apresentadas para discutir a evolução dos modelos atômicos.

No livro Q4 a radiação só é abordada no capítulo sobre modelos atômicos. Neste capítulo são apresentadas a radiação-X, as partículas- $\alpha$ e uma breve discussão sobre radiação eletromagnética, apenas citando alguns de seus tipos (micro-ondas, rádio, ultravioleta e visível).

Nos livros F1 e F2 não é utilizado o termo "radiação", mas sim ondas eletromagnéticas. No livro F1 as ondas eletromagnéticas (infravermelho, microondas, rádio, visível, raios X e gama) são abordadas em um capítulo sobre movimento ondulatório. Nenhum outro tipo de radiação é abordado neste material (livro F1). Já no livro F2 o assunto radiação é abordado em diferentes momentos: (i) no capítulo sobre ondas, no qual a radiação eletromagnética é descrita como o resultado da oscilação de um campo elétrico e um magnético perpendicular ao primeiro; (ii) em um capítulo exclusivo sobre ondas eletromagnéticas, no qual é abordada a interação de algumas radiações (X, rádio, TV e micro-ondas) com a matéria; (iii) em um capítulo sobre mecânica quântica, quando é abordado efeito fotoe- 
létrico e modelo atômico de Bohr e (iv) em um capítulo sobre partículas elementares, no qual são apresentados os decaimentos $\alpha$ e $\beta$, fusão e fissão nuclear.

\subsection{Forma de abordagem do assunto:}

Gouvêa e Machado (2005) acreditam que a contextualização não se resume a exemplificar um conteúdo, mas é necessário propor "situações problemáticas reais" e buscar o conhecimento necessário para entendê-las e solucionálas. Para Silva et al (2009), a contextualização inter-relaciona conhecimentos diferentes contribuindo para a estruturação de novos significados. E esses significados incorporam valores, pois destacam o cotidiano, favorecendo a formação de cidadãos com capacidade de discutir questões ambientais, sociais, econômicas (WARTHA \& FALJONI-ALÁRIO, 2005) e tecnológicas.

Nos livros Q1 e Q2 o tema radiação não é contextualizado. Nos capítulos que tratam radiação nuclear, os assuntos fissão e fusão nuclear são relacionados às bombas atômicas e de hidrogênio, relacionando-os indiretamente a malefícios ("Cada uma das bombas atômicas detonadas no Japão correspondia a cerca de 20 quilotons - poder destrutivo de 20 mil ton de dinamite. Aproximadamente 71 mil pessoas foram mortas instantaneamente em Hiroshima. (...) em Nagasáqui, 74 mil pessoas morreram (...). As mortes nos cinco anos subseqüentes, devidas à exposição à radiação, foram estimadas em 200 mil' (Livro Q2)).

Além disso, outros eventos trágicos ou de difícil resolução envolvendo radiação nuclear são citados, tais como o acidente radioativo na usina nuclear de Chernobyl (Ucrânia), o do Césio-137 em Goiânia ("em Goiânia - 1987 - uma cápsula de césio-137 deixada em local impróprio provocou a morte de 4 pessoas, além da contaminação de outras 150" (Livro Q1)) e o problema de armazenamento de lixo radioativo, originários de usinas nucleares ("...difíceis de reciclar, esses materiais apresentam uma dose residual de radioatividade potencialmente nociva à saúde humana e ao ambiente" (Livro Q1)).

Embora haja exemplos de aplicações e acidentes envolvendo radiações, eles não contribuem para o desenvolvimento de novos significados. No capítulo sobre modelo atômico, quando radiações eletromagnéticas são introduzidas, tanto no livro Q1 quanto no Q2, há apenas a apresentação do espectro eletromagnético, com desenhos de dispositivos que utilizam essas radiações, sem nenhuma explicação adicional. Para Liso et al (2002), esse tipo de abordagem não contribui para o desenvolvimento do conhecimento, pois não traz situações problemáticas que possam ser aplicadas à vida diária.

O livro Q3 inicia dois de seus capítulos sobre radiação nuclear com textos informativos e interativos sobre o assunto. Em diversos momentos do texto, os autores realizam perguntas ("você já foi exposto a algum tipo de radiação? As radiações nucleares são invenções humanas? A energia nuclear deve ou não ser utilizada? Que propriedade dos raios X permite que eles sejam utilizados na medicina?") buscando interagir com os estudantes. Logo depois, uma breve reflexão sobre o assunto é apresentada, tentando direcionar o estudante a uma resposta. 
O tema radiação nuclear é tratado, em diversos momentos, através de contexto histórico relacionado à sua descoberta. Emissões, transformações nucleares, datação radioativa, fissão e fusão nuclear são os principais assuntos abordados através do prisma histórico. Em diversos momentos do texto, há perguntas questionando os estudantes sobre o conteúdo ("os processos de emissões radioativas são transformações físicas ou químicas? O que acontece com um átomo que emite uma particula alfa? O que leva a radiação alfa a ser atraída pelo lado negativo do campo elétrico? Como podemos afirmar que o 'Pergaminho do Mar Morto', manuscrito hebreu do livro do Velho Testamento, possui mais de dois mil anos? Se é possivel transformar átomos de um metal em átomos de outro metal, por que os alquimistas não conseguiram fazer isso?’'). Acreditase que essas perguntas (forma de interação com os estudantes) auxiliam a aquisição do conhecimento, pois os estudantes têm a oportunidade de refletir sobre o conteúdo estudado a todo instante, não lendo apenas um texto contínuo.

No capítulo sobre modelos atômicos, a radiação eletromagnética ultravioleta é abordada indiretamente em um texto sobre camada de ozônio, que inicia o capítulo. Já no meio do capítulo a radiação novamente é abordada, dando ênfase à radiação-X. As radiações alfa e beta são apenas citadas para introduzir o modelo atômico de Rutherford. Ao descrever o modelo atômico de Bohr, há a apresentação do espectro eletromagnético, com destaque para a radiação visível, mas sem nenhum aprofundamento. No meio do capítulo, antes do modelo atômico de Bohr ser apresentado, é introduzido um texto sobre a radiação ultravioleta e os efeitos nocivos aos tecidos vivos, sem nenhum vínculo com o conteúdo anterior ou posterior.

No livro Q4 o tema radiação é abordado somente no capítulo sobre modelos atômicos, citando a descoberta da radiação-X por Röntgen, em 1895, e também da radioatividade a partir de sais de urânio, por Bequerel, em 1896. Nas páginas seguintes do capítulo, os autores citam quem observou e identificou (Rutherford) as radiações $\alpha, \beta$ e $\gamma$ e estudou os seus comportamentos na presença de um campo elétrico perpendicular às suas trajetórias.

$\mathrm{O}$ acidente com Cs-137, em Goiânia, é citado apenas em um exercício logo após a descrição das radiações $\alpha, \beta$ e $\gamma$. Além disso, o livro Q4 valoriza algumas radiações eletromagnéticas (visível, micro-ondas, rádio, TV, ultravioleta e $\mathrm{X}$ ) em um pequeno texto que introduz o motivo (trabalhos de Maxwell sobre eletromagnetismo) de essas radiações serem tratadas como apenas de um tipo (radiação eletromagnética). Outro ponto interessante abordado neste material (livro Q4) é a descrição da natureza ondulatória das radiações eletromagnéticas para introduzir o espectro eletromagnético. E por fim o material cita os espectros de emissão de átomos, relacionando-os com radiação eletromagnética.

A abordagem do tema radiação no livro F1 se fundamenta na discussão de radiações eletromagnéticas, no capítulo sobre movimento ondulatório. Neste material, as ondas eletromagnéticas infravermelhas, micro-ondas, rádio, visível, $\mathrm{X}$ e $\gamma$ são explicadas de acordo com a diferença em seus comprimentos de onda. Além disso, são explicadas algumas aplicações tecnológicas dessas 
radiações. Entretanto, não há nem mesmo citação de interação de radiações eletromagnéticas com a matéria. Acredita-se que essa abordagem é importante e necessária para o desenvolvimento de valores sobre as radiações.

A primeira abordagem sobre radiação apresentada no livro F2 é geral (no capítulo sobre ondas), descrevendo o que é uma radiação eletromagnética. $\mathrm{Na}$ sequência é apresentada a radiação visível, com sua respectiva faixa de frequência do vermelho $\left(4,3 \times 10^{14} \mathrm{~Hz}\right)$ ao violeta $\left(7,5 \times 10^{14} \mathrm{~Hz}\right)$ e o espectro eletromagnético, como um esquema que contém as frequências das ondas eletromagnéticas.

No capítulo sobre ondas eletromagnéticas, são apresentadas (i) algumas propriedades (velocidade de propagação e variação de campo elétrico que gera um campo magnético perpendicular ao primeiro) que as definem como tal e (ii) formas de interação da radiação-X, rádio, TV e micro-ondas com a matéria, em nível molecular e eletrônico.

No capítulo sobre partículas elementares, emissões $\alpha$ e $\beta$ são descritas como maneiras de estabilizar um átomo radioativo instável. Ao tratarem de fissão nuclear, é mencionada a liberação de radiações $\gamma$ e $\beta$, associada à liberação de uma grande quantidade de energia, característica da quebra de um átomo. Já ao tratarem de fusão nuclear, a liberação de radiação $\alpha$ é citada como forma de estabilização de um novo átomo formado.

Acredita-se que a abordagem das interações das radiações eletromagnéticas com a matéria, como é feita neste material (livro F2), é de importância considerável para o desenvolvimento do conhecimento pelos estudantes, pois eles terão a oportunidade de entender, por exemplo, como um alimento se aquece ou o milho de pipoca estoura dentro de um forno de micro-ondas.

\section{Conhecimento prévio dos estudantes}

Schnetzler e Aragão (1995) defendem que as concepções prévias dos estudantes são resistentes à mudança e os fazem entender os propósitos do processo de ensino diferentemente do professor. Esses autores acreditam que a evolução conceitual dos alunos se dará quando forem levadas em consideração as concepções prévias acerca de conceitos fundamentais da Química, e não o simples cumprimento do programa curricular.

Através de cinco perguntas formuladas pelo autor, coletaram-se dados para identificar algumas concepções comuns dos alunos sobre as radiações. As respostas mais proeminentes são citadas neste trabalho.

Você já ouviu falar sobre radiações? Onde?

Esta foi a primeira questão apresentada aos estudantes analisados neste trabalho. Todos os estudantes citaram, pelo menos, duas respostas, num total de 161 itens mencionados. A Figura 1 mostra um gráfico comparativo para as respostas dos estudantes. 


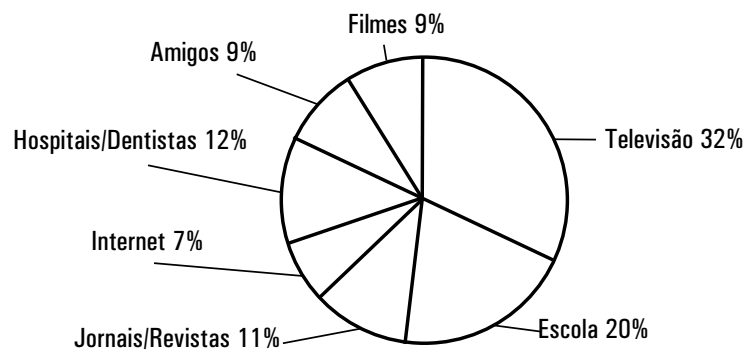

Figura 1. Principais fontes de informação sobre radiação.

Os programas de televisão são conhecidos por ser um dos principais meios de informação da população brasileira e isso foi demonstrado neste trabalho, quando $32 \%$ das citações dos alunos indicaram-na como fonte de informação sobre radiação. A segunda maior fonte de informação dos estudantes sobre o assunto é a escola, lembrada em $20 \%$ das respostas. Esse resultado mostra que, embora os alunos ainda não tenham estudado o conteúdo radiações no currículo de Química, em algum momento eles ouviram a palavra radiação, em sala de aula, seja nas aulas de química ou de outras disciplinas.

A análise dos dados da primeira questão mostrou ainda que 12\% das respostas estão associadas a hospitais e consultórios dentários, indicando uma referência direta ao uso de radiação-X para obtenção de radiografias de membros fraturados ou arcada dentária. Jornais e revistas impressas também foram lembrados em 11\% das respostas dos estudantes, indicando que os estudantes ainda leem alguns materiais informativos impressos, mesmo com a grande presença da internet, que foi lembrada em apenas 7\% das citações. As conversas entre amigos também foram citadas como fonte de informação sobre radiação, correspondendo a $9 \%$ do total de fontes de informação lembradas.

Os estudantes também se lembraram de citar filmes de ficção científica como fonte de informação sobre radiações, representando $9 \%$ das respostas. Os filmes lembrados foram apenas os da série $X-M e n$, possivelmente por serem recentes e estarem na programação de alguns canais de TV aberta.

\section{Como você definiria o termo radiação?}

A segunda questão proposta aos estudantes foi sobre o seu entendimento a respeito do termo radiação. Do total de estudantes (77 alunos questionados), 55\% responderam à questão, definindo o termo. A seguir, são mostradas três respostas apresentadas pelos estudantes.

"São coisas altamente perigosas, pois podem causar câncer de pele. Dependendo do tipo da radiação, pode causar a morte."

"A radiação é uma coisa perigosa que pode causar câncer de pele ou aquecimento global."

"A radiação é uma energia que pode alterar e danificar os seres vivos."

As três citações anteriores mostram que os seus autores não sabem 
conceituar o termo radiação, mas associam-no a problemas. Os fatos apresentados por esses estudantes revelam uma associação errônea do termo radiação apenas a malefícios. Entre os estudantes que responderam a essa questão, houve aqueles que associaram o termo radiação a ondas eletromagnéticas. Observe algumas respostas a seguir.

"... são ondas eletromagnéticas que saem de um elemento".

"São ondas com alta velocidade e energia que podem transformar uma matéria."

As respostas desses dois estudantes revelam uma influência de conteúdos estudados anteriormente, por exemplo, (i) modelo atômico de Bohr, que no livro texto dos estudantes (livro 1) aborda também as radiações eletromagnéticas, de maneira bem geral, e (ii) fenômenos como a maior incidência de radiação ultravioleta na superfície da Terra nas últimas décadas e os prejuízos associados a isso (estudados por exemplo na disciplina de biologia).

A dificuldade apresentada pelos estudantes em conceituar o termo radiação já era esperada, pois a princípio eles ainda não haviam estudado o conteúdo, que pertence ao programa curricular da segunda série do Ensino Médio.

\section{Radiação causa beneficios on malefícios? Quais?}

A terceira questão apresentada aos estudantes tentou verificar a relação radiação/matéria, vinculada a malefícios ou benefícios. A maioria dos estudantes $(82 \%)$ relacionou radiação a malefícios à saúde humana ou ao meio ambiente, conforme é apresentado nos trechos a seguir. soas."

"Radiação é muito perigoso, principalmente em contato com as pesreza".

“... podem ser ondas radioativas que são prejudiciais à saúde e à natumorte."

“É uma coisa perigosa, pois pode provocar câncer de pele, mutação ou

É notória a associação que estes estudantes fazem do termo radiação à radioatividade ou à radiação ionizante. Essa visão sobre radiação também é observada por Henriksen e Jorde (2001) e Alsop e Watts (1997) em trabalhos sobre concepções de estudantes sobre radiações.

A relação entre radiação e malefícios e também benefícios foi a resposta de $10 \%$ dos estudantes questionados. A transcrição apresentada a seguir sintetiza as respostas dadas por esses estudantes.

"...radiação é um ato que modifica e transforma a natureza, ocorrendo vários processos de destruição e de melhorias para o mundo”.

Concepções semelhantes à deste estudante é o que se espera ao estudar radiações no Ensino Médio, pois demonstra uma visão consciente de que radiação pode estar associada a malefícios das radiações ionizantes, por exemplo, ou a benefícios oferecidos pela utilização de radiações eletromagnéticas em dispositivos tecnológicos como fornos de micro-ondas, aparelhos de rádio ou TV. 

ção? Qual(is)?

Hoje, ou em algum dia de sua vida, você já ficon exposto a algum tipo de radia-

Os estudantes de Ensino Médio também foram avaliados sobre a possibilidade de exposição a algum tipo de radiação. Entre os estudantes questionados, apenas 10\% indicaram nunca terem se exposto à radiação, mostrando a dificuldade em relacionar o termo com fenômenos e dispositivos presentes no seu cotidiano. Os outros 90\% dos estudantes relataram já terem se exposto à radiação, indicando pelo menos dois tipos de exposição (num total de 177 fontes de exposição mencionadas), associando principalmente à radiação X (40\%) e solar (33\%). A Figura 2 mostra um gráfico comparativo para as respostas dos estudantes.

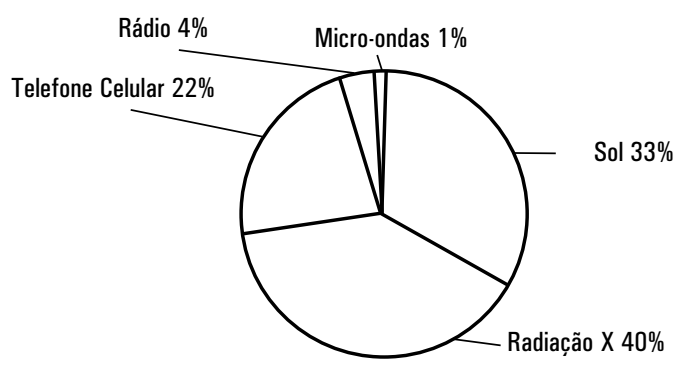

Figura 2. Possíveis fontes de radiação a que os estudantes já ficaram expostos.

A indicação de radiação-X em 40\% dos itens mencionados mostra que uma parcela significativa dos estudantes avaliados sabe que o ato de tirar uma simples radiografia de um membro fraturado, por exemplo, guarda uma relação com radiação. Já os 33\% dos itens mencionados que se referem à radiação solar podem indicar consciência dos jovens em relação a problemas como buraco na camada de ozônio, maior incidência de câncer de pele devido à exposição ao sol e aquecimento global, que são fenômenos cada vez mais presentes na mídia. No entanto, esse resultado também indica que os estudantes não têm consciência que a radiação solar é composta por alguns tipos de radiação eletromagnética, como visível, ultravioleta e infravermelha.

A análise das respostas a este questionamento mostrou que $22 \%$ das fontes de radiação mencionadas pelos estudantes estão relacionadas à telefonia celular, entretanto, não ficou clara a relação entre o dispositivo e o tipo de radiação. Além disso, os estudantes não citaram se acreditam que os aparelhos celulares emitem ou usam radiação para funcionar.

Alguns outros estudantes mencionaram rádio, TV (4\%) e micro-ondas $(1 \%)$ como resposta ao questionamento. Entretanto, ao analisar essas respostas para a elaboração deste trabalho, surgiu a dúvida se esses estudantes estavam se referindo realmente às radiações eletromagnéticas ou aos dispositivos que as uti- 
lizam, pois todos esses estudantes (que citaram rádio e TV) também citaram telefone celular como um tipo de radiação. Essa dificuldade em entender se os estudantes citaram um tipo de radiação ou um dispositivo envolvido com radiações se deve possivelmente à abrangência da pergunta. Acredita-se que, se a pergunta fosse mais específica ("você já ficou exposto a algum tipo de radiação? Em caso positivo, essa radiação está vinculada a algum dispositivo tecnológico? Qual(is)?”), esse problema seria minimizado.

Os resultados da análise das respostas a esse questionamento indicam que os estudantes apresentam certo conhecimento sobre radiações, sabendo que algumas radiações estão presentes em suas vidas. Entretanto, não ficou claro se os estudantes conhecem as radiações eletromagnéticas como rádio e TV ou se apenas acreditam que os dispositivos tecnológicos com o mesmo nome emitem ou utilizam radiação.

\section{Quais os tipos de radiação de que você já ouviu falar? Cite-os.}

A última questão utilizada para avaliar o conhecimento prévio dos estudantes foi sobre os tipos de radiações de que eles já ouviram falar, sem a necessidade de conhecerem-nas ou já terem ficado expostos a elas. Todos os estudantes indicaram pelo menos duas respostas a este questionamento, em um total de 152 citações.

A radiação solar foi a mais citada pelos estudantes, correspondendo a $29 \%$ do total de respostas dadas. Novamente ficou clara a falta de conhecimento dos estudantes a respeito da radiação solar, que é composta principalmente por radiação visível, ultravioleta e infravermelha. A segunda radiação mais lembrada pelos estudantes foi a X, representando $26 \%$ do total de respostas, conforme é mostrado na Figura 3.

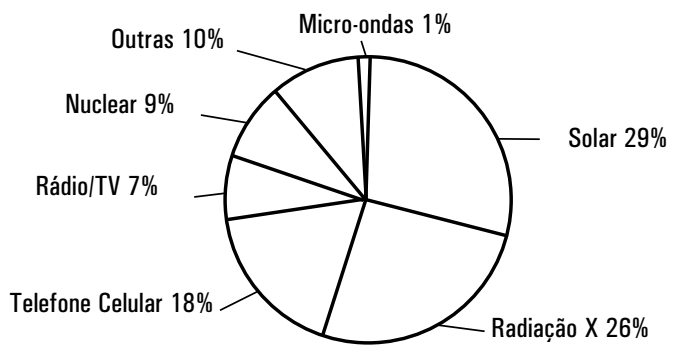

Figura 3. Fontes de radiação lembradas pelos estudantes.

Os estudantes, assim como nas respostas à quarta questão, associaram telefone celular a um tipo de radiação (18\% das respostas), entretanto essa radiação não foi identificada. Já $9 \%$ das respostas apresentadas pelos estudantes indicaram a radiação nuclear, através de citações como núcleos atômicos instáveis de urânio, plutônio ou simplesmente núcleos radioativos. 
Os termos rádio e TV foram lembrados em 7\% das respostas, assim como micro-ondas em 1\% das respostas. Entretanto não ficou claro se os estudantes faziam associações aos dispositivos eletrônicos ou às radiações eletromagnéticas com os mesmos nomes. Conflito igual foi evidenciado nas respostas à quarta questão do questionário, já apresentado.

Fenômenos e objetos que não estão relacionados diretamente com radiações também foram lembrados em 10\% das respostas. Entre essas respostas estão computador, Lua, som (ondas sonoras) e até mesmo poluição do ar. Esse resultado mostrou a dificuldade de os estudantes compreenderem o termo radiação e identificar suas fontes (tecnologias que utilizam radiação - telefones celulares, fornos de micro-ondas, aparelhos de CD e DVD, controles remotos, etc.

\section{Descrição do material didático}

As respostas dos estudantes ao questionário e a falta de abordagem nos livros didáticos analisados (incluindo os livros textos adotados, Q1 e F1) de alguns aspectos sobre radiação incentivaram o desenvolvimento de um material didático, na forma de unidade temática sobre radiações, que foi adotado em duas turmas de terceiro ano do Ensino Médio.

O desenvolvimento do material didático objetivou: (i) minimizar a deficiência de abordagem sobre radiações encontrada em alguns livros didáticos de Química e Física; (ii) mostrar que o tema radiação é relevante para a sociedade e o meio ambiente e (iii) apresentar fontes e aplicações de radiação e suas relações com o cotidiano e o desenvolvimento tecnológico contemporâneo. Acredita-se que essa abordagem do tema radiação pode criar uma necessidade de busca de informações, motivando o processo de aprendizagem.

O material didático foi dividido em três partes principais:

Introdução dirigida ao estudante com o objetivo de motivar o aluno ao estudo do tema. O texto apresenta, em diversos momentos, perguntas direcionadas aos estudantes e elementos gráficos (desenhos, imagens, modelos) com o objetivo de introduzir, interagir e direcionar a aquisição do conhecimento pelos estudantes. Nesta parte do material, o termo radiação é descrito e as radiações nucleares e eletromagnéticas são caracterizadas. Abordagem das radiações nucleares e eventos radioativos. As emissões radioativas nucleares do tipo $\alpha, \beta$ e $\gamma$ foram abordadas através de fatos históricos que envolvem o seu descobrimento e algumas propriedades que as caracterizam, tais como poder de penetração, ionização da matéria e interação com campo elétrico (partículas $\alpha$ e $\beta$ desviam na presença de um campo elétrico, pois são carregadas positiva e negativamente, diferentemente da radiação $\gamma$, que não apresenta carga elétrica). As radiações nucleares foram também relacionadas ao decaimento radioativo de um núcleo instável de um átomo e suas aplicações tecnológicas, como a datação por C-14, que relaciona o tempo de meia vida de átomos de carbono radioativo presente em organismos baseados em carbono, com a época em que ele possivelmente estava vivo. Além disso, foram citados exemplos de elementos químicos radioativos que se encontram presentes em bai- 
xíssimo teor em objetos e organismos do cotidiano, tais como Urânio-235 e Rádio226, presentes em rochas, e Potássio-40 e Carbono-14, presentes em plantas e em nosso organismo. Exemplos de aplicação comuns para essas radiações foram citados, tais como gamagrafia (espécie de radiografia de peças metálicas, bastante utilizada na indústria de aviação, para detectar pequenos defeitos estruturais ou rachaduras), esterilização de materiais farmacêuticos, cirúrgicos e alimentos sensores de detectores de fumaça.

Abordagem das radiações eletromagnéticas e interação com a matéria. As radiações eletromagnéticas foram introduzidas, de uma maneira geral, a partir da descrição de seus movimentos ondulatórios, característicos de todas essas radiações. As radiações$\mathrm{X}$, infravermelhas, ultravioleta, rádio, TV e micro-ondas (radiação $\gamma$ também é um tipo de radiação eletromagnética, mas que foi tratada na parte sobre radiação nuclear) foram as radiações eletromagnéticas abordadas no material elaborado. Para trabalhar cada uma das radiações, utilizou-se como ponto de partida os dispositivos cotidianos ou situações que as utilizam. A radiação- $X$, devido à sua grande disseminação no meio médico ou odontológico, foi trabalhada a partir de seu uso indiscriminado para obtenção de radiografias odontológicas, de membros fraturados e/ou órgãos internos, devido ao seu poder de penetração acentuado. Além disso, foi dada atenção à possibilidade de modificação de funções e estruturas de moléculas e células em organismos vivos, devido à alta energia contida nesta radiação, que é conhecida também como um tipo de radiação ionizante (que pode retirar elétrons, formando íons ou radicais quando interage com moléculas de um determinado material). Já a micro-ondas, que é uma radiação eletromagnética não ionizante, foi abordada através da sua interação com a matéria em fornos de micro-ondas, cada vez mais presentes nas cozinhas brasileiras. O princípio básico do forno de micro-ondas é a produção da radiação, que interage principalmente com as moléculas de água contida nos alimentos, fazendo essas moléculas girar e atritarem umas às outras, aquecendo o sistema, que não atinge temperaturas superiores a $100^{\circ} \mathrm{C}$ (temperatura de ebulição da água). Além disso, foi mencionada a relação da radiação de micro-ondas com a transmissão de informações em telefonia celular e a diferença (menor energia) entre a radiação utilizada neste caso e a usada nos fornos, citados anteriormente. As radiações infravermelhas, ultravioleta, rádio e TV foram também abordadas considerando a interação com a matéria, suas relações com dispositivos tecnológicos presentes no dia a dia e com fenômenos de escala mundial bastante discutidos nos últimos anos, tais como o aquecimento global e o buraco na camada de ozônio.

O texto de todo o material didático apresenta uma mescla de perguntas, esquemas e propostas de exercícios para os estudantes se questionarem e refletirem sobre o assunto. Acredita-se que através da utilização deste material didático é possível a criação de relações entre disciplinas, tais como (a) Biologia, descrevendo os principais efeitos das radiações quando interagem com sistemas biológicos; (b) Física, facilitando o entendimento do comportamento ondulatório das radiações eletromagnéticas; (c) Geografia, permitindo a discussão e reflexão sobre aspectos políticos e sociais dos benefícios e malefícios associados à utilização de energia nuclear para produção de energia e a questão do aquecimento global e buraco na camada de ozônio.

A abordagem contextualizada do tema radiação permite retirar o estudante da condição de expectador passivo, possibilitando a ele interagir com a sua aquisição do conhecimento, como os Parâmetros Curriculares Nacionais desejam.

As aulas sobre radiação, utilizando o material didático, foram realizadas em oito encontros de 50 minutos. O professor que lecionou as aulas foi 
orientado também a valorizar a voz dos estudantes, permitindo que eles apresentassem suas concepções prévias, discutindo e refletindo sobre o assunto.

\section{Conhecimento adquirido pelos estudantes}

Três semanas após o tema radiações ser abordado utilizando o material didático desenvolvido, foi apresentado aos alunos o mesmo questionário aplicado para verificar os seus conhecimentos prévios. Essa ação objetivou verificar a aquisição do conhecimento pelos estudantes, analisando as possíveis mudanças em seus discursos.

Através de cinco perguntas formuladas pelo autor, coletaram-se dados sobre o conhecimento dos estudantes sobre radiações. As respostas mais relevantes são apresentadas a seguir.

\section{Você já ouviu falar sobre radiações? Onde?}

Todos os estudantes responderam a esta questão e pelo menos dois exemplos foram citados por cada um, num total de 162 itens mecionados. A Figura 4 mostra um gráfico comparativo para as respostados dos estudantes.

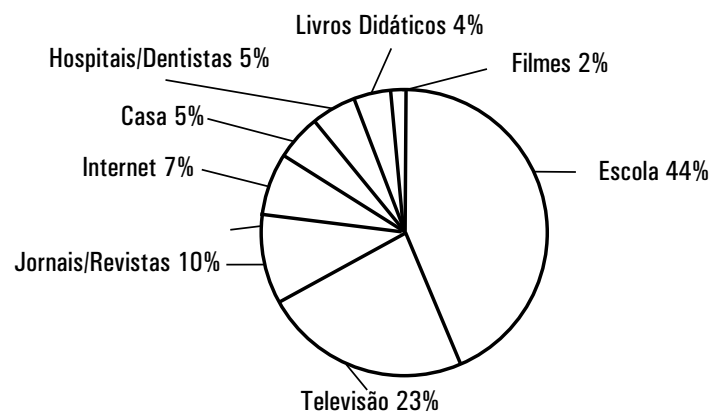

Figura 4. Fontes de informações sobre radiação, após o conteúdo ser lecionado.

Pelo fato de o tema radiações ter sido lecionado três semanas antes da aplicação do questionário, acreditava-se que o número de indicações com referência à escola se elevasse em relação às respostas antes de o tema ser abordado $(20 \%)$ e esse resultado foi observado, quando $44 \%$ das indicações realizadas pelos estudantes apontaram a escola/sala de aula como a principal fonte de informação sobre radiações.

A segunda maior fonte de informação lembrada pelos estudantes foram os programas televisivos, representando $23 \%$ do total de indicações, um decréscimo de $9 \%$ em relação às indicações pré-conteúdo abordado. Jornais e revistas impressas foram lembrados em $10 \%$ das respostas dos estudantes, valor praticamente igual às citações prévias $(11 \%)$ ao conteúdo ser abordado. A internet também foi lembrada pelos mesmos $7 \%$ de itens citados no primeiro questionário. 
As porcentagens indicadas pelos estudantes para jornais, revistas e internet (total de 17\%) indicam que não houve mudança comportamental em relação à busca de informações em material informativo, pois no questionário inicial esses mesmos itens foram lembrados em 18\% do total de respostas, que também foram semelhantes (pós à 162 e pré à 161).

Hospitais e consultórios dentários mantiveram os 5\% de respostas dos estudantes como um dos locais onde se ouviu falar sobre radiações. O mesmo ocorreu com o item filmes, também lembrado em $2 \%$ das respostas, como no questionário pré-conteúdo abordado.

Livros didáticos foram a resposta de $4 \%$ dos estudantes a este questionamento, o que indica que os alunos, embora não tenham buscado novas informações na internet, em jornais e/ou revistas (ou não tenham citado como respostas ao questionário), procuraram informações extras em seus próprios livros didáticos. Já 5\% das respostas indicaram que os estudantes ouviram o termo radiação em casa, o que sugere que os estudantes autores das respostas (oito alunos) conseguiram levar o conteúdo estudado em sala de aula para fora do ambiente escolar, possivelmente discutindo com os seus familiares. A resposta de um dos estudantes dá essa indicação ("até minha mãe se interessou por radiação").

\section{Como você definiria o termo radiação?}

A segunda questão proposta aos estudantes foi sobre o seu novo entendimento a respeito do termo radiação. Do total de estudantes (77 alunos), apenas 14\% não souberam definir o termo. Esse resultado mostra uma evolução no entendimento sobre radiações, pois antes de o conteúdo ser lecionado $45 \%$ dos estudantes nem mesmo responderam à questão.

Entre os estudantes que definiram o termo radiações, $80 \%$ vincularam-no a ondas eletromagnéticas e radiações nucleares, enfatizando que as radiações eletromagnéticas podem estar presentes no cotidiano de todos. Já os outros $20 \%$ de estudantes atrelaram o termo exclusivamente a radiações e processos nucleares, demonstrando problemas na aprendizagem do conteúdo. Observe as citações a seguir.

“...radiação é o desprendimento de partículas de um átomo”.

"... tudo tem ondas radioativas".

"é a capacidade de um átomo ultrapassar (no sentido de atravessar) $)^{3}$ o outro".

Diferentemente do que ocorreu no questionário prévio, nenhum estudante vinculou a definição do termo radiação a malefícios e/ou benefícios.

\section{Radiação causa benefícios ou malefícios? Quais?}

Esta questão procurou verificar a relação entre radiação e matéria, a partir de malefícios e/ou benefícios, após o tema radiações ser lecionado em sala de aula. A partir da análise das respostas dos estudantes foi possível verificar uma diminuição de $42 \%$ em relação ao número de alunos $(82 \%)$ que fizeram essa relação antes de o conteúdo ser trabalhado em sala de aula.

Já a associação entre radiação tanto com malefícios quanto com benefícios foi resposta de 50\% dos estudantes. Esse resultado mostra um avanço na 
compreensão do conteúdo, pois o questionário prévio indicou apenas $10 \%$ dos alunos com consciência de alguns malefícios e benefícios das radiações. A seguir é mostrada a resposta de um dos estudantes que cita a relação entre malefícios, benefícios e radiações.

"A radiação nos ajuda em termos de saúde ou de comodidades, que vem da tecnologia, mas ela causa danos quando não usada da melhor forma (bomba atômica) ou em excesso (muitas radiografias sem necessidade)."

É possível inferir que o estudante autor da resposta compreendeu o conteúdo e consegue fazer relações entre radiação e algumas tecnologias presentes no cotidiano e que utilizam ou emitem algum tipo de radiação. Esse era o resultado desejado para todos os estudantes, mas apenas esse elaborou uma resposta capaz de demonstrar o entendimento esperado.

Hoje, ou em algum dia de sua vida, você já ficon exposto a algum tipo de radiação? Qual(is)?

Os estudantes foram novamente avaliados sobre a possibilidade de exposição a algum tipo de radiação. A maior parte dos estudantes indicou dois itens, num total de 157 mencionados.

A radiação solar foi a radiação mais lembrada pelos estudantes, representando 32\% do total de respostas (Figura 5), praticamente o mesmo valor (33\%) citado nas respostas do questionário prévio. Já a radiação-X foi lembrada em 24\% das respostas mencionadas. Quando este dado é comparado com o obtido no questionário prévio $(40 \%)$, percebe-se um decréscimo significativo de $16 \%$, possivelmente devido à maior citação de outras radiações.

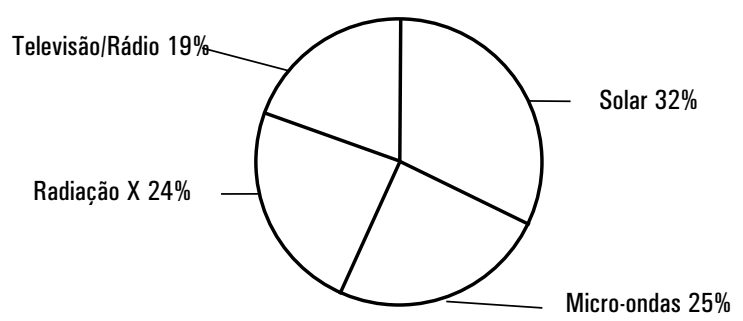

Figura 6. Principais fontes de radiação a que os estudantes estão expostos.

A radiação de micro-ondas foi citada em 25\% das respostas dos estudantes, mostrando a vinculação desta radiação ao uso de fornos de micro-ondas e telefones celulares, que foram citados isoladamente no questionário prévio, Figura 2. Já 19\% das respostas indicaram a exposição às radiações de rádio e TV, o que indica a possível compreensão de que essas radiações são bastante comuns e os dispositivos com os mesmos nomes utilizam-nas para funcionar.

Através das respostas a este questionamento, foi possível perceber que os estudantes citaram algumas importantes radiações que estão presentes no 
cotidiano e que foram abordadas no material didático utilizado para lecionar o conteúdo. Entretanto, percebeu-se que a radiação do tipo infravermelho não foi citada nenhuma vez, mesmo sendo trabalhada no material adotado.

Quais os tipos de radiação de que você já ouviu falar? Cite-os.

A última questão proposta foi respondida por todos os estudantes, num total de 140 itens mencionados. Todas as respostas correspondiam a radiações reais (micro-ondas, infravermelhas, $\mathrm{X}$, solar, rádio, TV e radiação nuclear) e não mais a computadores, Lua, som e poluição atmosférica, como foi verificado $(10 \%$ das respostas) para a mesma pergunta no questionário aplicado antes da abordagem do conteúdo (Figura 3). Esse resultado mostra ainda que os estudantes conseguiram associar os dispositivos eletrônicos (telefone celular e forno de micro-ondas) a um tipo de radiação (micro-ondas) e rádio e TV às radiações com os respectivos nomes, não citando mais os equipamentos. Essas pequenas melhorias sugerem um avanço na compreensão do tema radiações, que está amplamente presente em nossas vidas.

\section{CONSIDERAÇÕES FINAIS}

Acreditamos que a contextualização no ensino de Química pode oferecer aos estudantes a possibilidade de identificar o conteúdo a partir de contextos locais. Dessa maneira, poderá haver o desenvolvimento de significados imediatos daquilo que ele vê em sala de aula. Sendo assim, a abordagem do conteúdo radiações no Ensino Médio relacionado a alguns fenômenos e avanços tecnológicos pode transformar o ato de ensinar e aprender Química em algo mais agradável e com resultados mais expressivos.

A análise das concepções prévias dos estudantes permitiu verificar que a maioria deles $(82 \%)$ associava a terminologia "radiações" predominantemente a malefícios ao homem ou ao meio ambiente. Após o desenvolvimento do conteúdo, percebeu-se que essa associação foi alterada, através da abordagem contextualizada, que considerou também as formas de interação das diferentes radiações com a matéria. Essa abordagem contextualizada permitiu ainda a alguns dos estudantes (oito entre os 77 avaliados) romper a barreira entre a escola e o seu cotidiano, possibilitando a discussão de assuntos e fenômenos químicos com amigos e familiares (Figura 4). 


\section{AGRADECIMENTOS}

Os autores agradecem aos alunos de Ensino Médio que tiveram as suas respostas avaliadas para o desenvolvimento deste trabalho.

\section{NOTAS}

1 Brasil. Química: catálogo do Programa Nacional do Livro para o Ensino Médio: PNLEM/2008. Brasília: MEC, 2007.

2 As respostas dos estudantes não foram editadas, ou seja, os erros, se existirem, permanecem na escrita.

3 Comentário sublinhado adicionado pelos autores.

\section{LIVROS ANALISADOS}

FELTRE, R. Química. 6.ed. São Paulo: Moderna, 2004.

PERUZZO, F. M. \& CANTO, E. L. Química na abordagem do cotidiano. 3.ed. São Paulo: Moderna, 2003. SANTOS, W. L. P.; MÓL, G. S.; MATSUNAGA, R. T.; DIBS, M. F.; CASTRO, E. N. F.; SILVA, G. S.; SANTOS, S. M. O. \& FARIAS, S. B. Química \& sociedade. São Paulo: Nova Geração, 2005. MORTIMER, E. F. \& MACHADO, A. H. Química. São Paulo: Scipione, 2002.

MÁximo, A. \& AlvarengA, B. Física. São Paulo: Ed. Scipione, 1997.

SAMPAIO, J. L. P. \& CALÇADA, C. S. V. Física. 3a edição. São Paulo: Ed. Atual, 2008.

\section{REFERÊNCIAS BIBLIOGRÁFICAS}

ALSOP, S. \& WATTS, M. Sources from a Somerset village: A model for informal learning about radiation and radioactivity. Science Education, v. 81, 1997, p. 633-650.

BRASIL. Ministério da Educação (MEC), Secretaria de Educação Média e Tecnológica (Semtec). PCN + Ensino Médio: orientações educacionais complementares aos Parâmetros Curriculares Nacionais - Ciências da Natureza, Matemática e suas Tecnologias. Brasília: MEC/Semtec, 2002.

BROWN, J. S.; A., COLLINS \& DUGUID, P. Situated cognition and the culture of learning. Educational Researcher, v. 18, 1989, p. 32-42.

CARDOSO, E. M. Aplicações da energia nuclear: apostila educativa. Disponível em: <http://www.cnen.gov.br/ensino/apostilas/aplica.pdf>. Acesso em 22 de abril de 2008.

GODIM, M. S. C. \& MÓL, G. S. Saberes populares e ensino de Ciências: possibilidades para um trabalho interdisciplinar. Química Nova na Escola. São Paulo, n. 30, 2008, p. 3-9.

GOUVEA, L. R. \& MACHADO, A. H. Trilhando caminhos para compreender a contextualização no ensino de Química. 2005. Monografia (Graduação em Química Licenciatura) - Faculdade de Educação, Universidade Federal de Minas Gerais, Belo Horizonte, 2005.

HENRIKSEN, E. K. \& JORDE, D. High school students' understanding of radiation and the environment: can museums play a role? Science Education, v. 85, n. 2, 2001, p. 189-206.

LAJOLO, M. P. Livro didático: um (quase) manual de ensino. Em Aberto, Brasília, v. 16, n. 69, 1996, p. $40-49$.

MUNFORD, D. \& LIMA, M. E. C. C. Ensinar ciências por investigação: em quê estamos de acordo? Ensaio, Belo Horizonte, v. 9, n. 1, jul. 2007.

PEREIRA, O. da S. Raios cósmicos: introduzindo Física moderna no $2^{\circ}$ grau. 1997. Dissertação (Mestrado em Ensino de Ciências) - Instituto de Física e Faculdade de Educação, Universidade de São Paulo, São Paulo, 1997.

POMEROY, D. Science education and cultural diversity: mapping the field. Studies in Science Education, n. 24, 1994, p. 49-73.

RICARDO, E.C. Implementação dos PCN em sala de aula: dificuldades e possibilidades. Física na Escola. São Paulo, v. 4, n. 1, 2003, p. 8-11. 
SCHNETZLER, R. P. \& ARAGÃO, R. M. R. Importância, sentido e contribuições de pesquisas para o ensino de Química. Química Nova na Escola, São Paulo, n. 1, 1995, p. 27-31.

SILVA, R. T.; CURSINO, A. C. T.; AIRES, J. A. \& GUIMARÃES, O. M. Uma análise dos artigos publicados na seção "Experimentação no ensino de química" da revista Química Nova na Escola 2000-2008. Ensaio, Belo Horizonte, v. 11, n. 2, p. 245-261.

WARTHA, E.J. \& FALJONI-ALÁRIO, A. A contextualização no ensino de Química através do livro didático. Química Nova na Escola, São Paulo, n. 22, 2005, p. $42-47$. 
